\title{
Mortality in alcoholics with autonomic neuropathy
}

\author{
R H JOHNSON, B J ROBINSON
}

From the John Radcliffe Hospital, Headington, Oxford, UK and the Wellington School of Medicine, Wellington, New Zealand

SUMMARY Seventy-nine male chronic alcoholics who had been tested for autonomic neuropathy using four tests of vagus nerve function were followed for up to 7 years (mean $5 \cdot 5$ years). Thirty-two subjects had no vagal neuropathy, 25 had one abnormal test and 22 had two or more abnormal vagal function tests and two of these also had orthostatic hypotension. There were no differences between the reported alcohol consumptions and evidence of central or peripheral nerve or liver damage between the three groups. Twelve patients died during the follow-up period. At 7 years the percentage survival for the subjects with no evidence of vagal neuropathy was $91 \%$, with one abnormal test it was $66 \%$ and with two or more abnormal tests it was $79 \%$. The expected percentage survival for each of the group was $94 \%, 91 \%$ and $88 \%$ respectively. The results suggest that evidence of vagal neuropathy in chronic alcoholics is associated with a significantly higher mortality than in the general population and that deaths due to cardiovascular disease are a major cause.

In 1980 we showed that chronic damage to the vagus nerve may be a feature of alcoholic polyneuropathy and could be identified by simple physiological observations. ${ }^{1}$ A previous study had shown evidence of pathological changes in vagus nerve in four patients with alcoholic neuropathy in whom dysphonia and dysphagia were prominent clinical features. ${ }^{2}$ The voice and swallowing problems were apparently due to varying degrees of degeneration of the vagus nerve and one of the four patients also had degeneration of nerves in sympathetic tracts and had clinical symptoms of hypothermia and hypotension due to sympathetic dysfunction. Parasympathetic dysfunction affecting the vagus nerve has been confirmed in heavy drinkers who may show depressed reflex heart rate responses. $^{34}$ Sympathetic dysfunction is, however, rare $^{5}$ although orthostatic hypotension may occur in a few patients. ${ }^{6}$ In diabetes mellitus autonomic nervous system dysfunction is a finding with a grave prognosis. In one series diabetics with symptoms of autonomic neuropathy and abnormal autonomic function tests had a mortality rate after 5 years of $56 \% .^{7}$ In diabetes however, the clinical condition is a continuing one and orthostatic hypotension is more frequent. In alcoholics neither feature is of such

Address for reprint requests: $\operatorname{Dr} \mathbf{R} \mathrm{H}$ Johnson, Director of Postgraduate Medical Education, John Radcliffe Hospital, Headington, Oxford OX39DU, UK.

Received 4 August 1987 and in revised form 9 November 1987: Accepted 17 November 1987 significance; alcoholics may withdraw from alcohol and this may lead to improvement in autonomic function tests; ${ }^{8}$ also, alcoholics may withdraw permanently from alcohol.

In order to assess the significance of abnormal autonomic function in the prognosis of chronic alcoholics we have investigated the mortality in 79 alcoholics who had been studied with four tests of autonomic activity between 3.5 and 7 years previously. Our results indicate there is a highly significant increase in death rate although of a smaller degree than occurs in patients similarly affected in diabetes mellitus.

\section{Subjects and methods}

\section{Patients}

Seventy-nine male alcoholics were assessed for autonomic function between June 1979 and March 1983. They were aged between 33 and 69 years (mean 51.6) when first studied and had been drinking between 100 and $300 \mathrm{~g}$ ethyl alcohol daily for 10 to 40 years. At the time of assessment the subjects were undergoing rehabilitation and had abstained from alcohol for 2 weeks to 3 years (mean 4 months). None of the subjects had clinical symptoms of hypertension or heart disease but had varying degrees of alcohol-related neurological and hepatic damage. Whether or not the alcoholics survived up to 7 years after testing was determined through surveillance of death certificates as described under Statistics below.

Tests of autonomic nervous function

All patients were tested for autonomic neuropathy using the following tests: 
Postural change The patient lay supine. Following a period of 15 min supine rest the subject's blood pressure (BP) and heart rate (HR) were recorded three times using an arm sphygmomanometer with built-in microphone and electrocardiograph (ECG). The subject then stood. HR was continuously monitored at a fast chart speed $(50 \mathrm{~mm} / \mathrm{s})$, and the $30: 15$ ratio calculated as the ratio of the $R-R$ interval at beat 30 after standing (approximate time of longest interval) to the $\mathbf{R}-\mathbf{R}$ interval at beat 15 after standing (approximate time of shortest interval). A ratio of $>1.03$ was considered normal. ${ }^{9}$ Blood pressure change on standing was also determined. A fall of more than $20 \mathrm{mmHg}$ systolic pressure and $10 \mathrm{mmHg}$ diastolic pressure was considered abnormal.

Valsalva manoeuvre The patient was studied supine and was asked to blow through a mouthpiece and tubing attached to an anaeroid manometer for $15 \mathrm{~s}$. A small leak was provided in the manometer to prevent the subject maintaining pressure with the cheek muscles and he was asked to maintain an expiratory pressure of $40 \mathrm{mmHg}$. HR was recorded continuously throughout and for $30 \mathrm{~s}$ following release of pressure, on the ECG at a fast chart speed $(50 \mathrm{~mm} / \mathrm{s})$. The Valsalva ratio was calculated as the ratio of the longest pulse interval after the manoeuvre to the shortest pulse interval during the manoeuvre. ${ }^{10} \mathrm{~A}$ ratio of $>1.2$ was considered normal. ${ }^{11}$

Deep breathing The patient was trained to breathe deeply at a rate of six breaths/minute while supine. HR was then monitored continuously on the ECG at $50 \mathrm{~mm} / \mathrm{s}$ as the subject breathed deeply for 1 minute. The HR rate change with breathing was calculated from the average maximum pulse interval during deep expiration and the average minimum pulse interval during deep inspiration. ${ }^{1213} \mathrm{~A}$ change of heart rate of $>15$ beats $/ \mathrm{min}$ was considered as normal. ${ }^{14}$

Atropine $(1.8 \mathrm{mg})$ was administered intravenously at a rate of $0.6 \mathrm{mg} / \mathrm{ml} / \mathrm{min}$, with an interval of 1 minute between each $0.6 \mathrm{mg}$ dose. $\mathrm{HR}$ was monitored throughout infusion of atropine and until it reached a maximum (which took up to 5 to 10 minutes). The maximum change in $\mathrm{HR}$ from rest was calculated. An increase of heart rate of $>20$ beats $/ \mathrm{min}$ was considered as normal. ${ }^{1315}$

The normal values given for each of the tests above are from published sources. ${ }^{9-15}$ The minimum values obtained in 17 age-matched normal male control subjects studied in our laboratory were as follows: $30: 15$ ratio: 1.07 ; Valsalva ratio: 1.33 ; deep breathing: 17 beats $/ \mathrm{min}$; atropine: 33 beats/min. These values are generally higher than published data and might have appeared to bias the data towards our conclusion. The published data have therefore been used.

\section{Clinical assessment of peripheral and central nervous systems} damage

Subjects were examined and scored for each of the following neurological abnormalities:

1. Absent ankle or knee jerks.

2. Absent vibration sense $(128 \mathrm{~Hz})$ at ankles or knees.

3. Amnesia (inability to repeat six serial numbers).

4. Dementia (inability to recall date or home address or to do "100 minus 7" test).

5. An abnormal tandem gait test (instability) in walking heel to toe along a straight line).

6. A positive Romberg's test.
Clinical assessment of liver damage

Subjects were physically examined for liver enlargement and tenderness, spider naevi, jaundice and evidence of hormonal dysfunction. Blood was also taken for measurement of serum enzymes (gamma-glutamyal transferase, alanine transaminase, alkaline phosphatase), albumin levels and prothrombin time to assess liver function.

\section{Statistics}

The study date was taken as the 30 June 1986. This allowed a maximum follow up of 7 years. The mean follow up period was 5.5 years. Deaths which had occurred up to the time of the study date were identified from surveillance of all New Zealand death certificates. Based on the Eighth Revision of the International Classification of Diseases, the major cause of death was identified from among causes appearing on the death certificate. Expected rates of death from all causes and some selected causes were calculated for each age group on the basis of the mortality of the New Zealand male population in 1983 (the mid point of the study). Survival Curves were calculated using standard methods ${ }^{16}$ and results were analysed statistically using chi-squared and log rank testing. ${ }^{17}$

\section{Results}

\section{Autonomic function}

Of the 79 subjects that were examined, 32 had no evidence of vagal neuropathy, 25 subjects had one abnormal test result and 22 subjects had two or more abnormal results (table 1). Two subjects who both had abnormal results for all four autonomic function tests also had orthostatic hypotension (falls of 140/70 to $110 / 55$ and $150 / 95$ to $85 / 50 \mathrm{mmHg}$ respectively). The subjects were divided into these three groups for fur-

Table 1 Data of the alcoholic subjects grouped according to number of abnormal vagal function test results

\begin{tabular}{|c|c|c|c|}
\hline & $\begin{array}{l}\text { No evidence } \\
\text { of vagal } \\
\text { neuropathy }\end{array}$ & $\begin{array}{l}\text { One } \\
\text { abnormal } \\
\text { test }\end{array}$ & $\begin{array}{l}\text { Two or more } \\
\text { abnormal } \\
\text { tests }\end{array}$ \\
\hline $\begin{array}{l}\text { Number of subjects } \\
\text { Age (years) } \\
\text { Daily alcohol }\end{array}$ & $\begin{array}{l}32 \\
49 \cdot 4(8 \cdot 7)\end{array}$ & $\begin{array}{l}25 \\
55(7 \cdot 0)\end{array}$ & $\begin{array}{l}22 \\
57(7 \cdot 2)\end{array}$ \\
\hline $\begin{array}{l}\text { consumption (g/day) } \\
\text { Duration (years) }\end{array}$ & $\begin{array}{l}216(76) \\
21(9)\end{array}$ & $\begin{array}{c}236(64) \\
25(5)\end{array}$ & $\begin{array}{c}240(52) \\
28(8)\end{array}$ \\
\hline $\begin{array}{l}\text { Duration of } \\
\text { follow-up (years) }\end{array}$ & $5 \cdot 3(1 \cdot 3)$ & $5 \cdot 6(1 \cdot 1)$ & $5.5(1.0)$ \\
\hline $\begin{array}{l}\text { (percentage of group) } \\
\text { Evidence of damage to: }\end{array}$ & $\%$ & $\%$ & $\%$ \\
\hline $\begin{array}{l}\text { Liver } \\
\text { CNS } \\
\text { PNS }\end{array}$ & $\begin{array}{l}31 \\
41 \\
59\end{array}$ & $\begin{array}{l}20 \\
44 \\
56\end{array}$ & $\begin{array}{l}32 \\
45 \\
64\end{array}$ \\
\hline $\begin{array}{l}\text { Abnormal vagal tests: } \\
30: 15 \text { ratio } \\
\text { Valsalva ratio } \\
\text { Deep breathing } \\
\text { Atropine }\end{array}$ & $\begin{array}{l}0 \\
0 \\
0 \\
0\end{array}$ & $\begin{array}{r}48 \\
8 \\
40 \\
4\end{array}$ & $\begin{array}{l}86^{\circ} \\
55 \\
91 \\
82\end{array}$ \\
\hline
\end{tabular}

Age, alcohol consumption and durations are shown as mean, (SD) CNS: Central Nervous System; PNS: Peripheral Nervous System. There are no significant differences between the groups except for the results of autonomic function tests. 
Table 2 Numbers of deaths in alcoholic subjects, as compared with expected deaths in the general population, by cause of death

\begin{tabular}{|c|c|c|c|c|c|}
\hline \multirow[b]{2}{*}{ Cause of death } & \multicolumn{2}{|c|}{ Total number of deaths } & \multicolumn{3}{|c|}{ Deaths observed and degree of vagal neuropathy } \\
\hline & Observed & Expected & $\begin{array}{l}\text { No abnormal } \\
\text { tests }\end{array}$ & $\begin{array}{l}\text { One abnormal } \\
\text { test }\end{array}$ & $\begin{array}{l}\text { Two or more } \\
\text { abnormal tests }\end{array}$ \\
\hline $\begin{array}{l}\text { All Diseases } \\
\text { Malignant neoplasms } \\
\text { Cardiovascular system } \\
\text { Heart disease } \\
\text { Cerebrovascular disease } \\
\text { Respiratory system } \\
\text { Accidents }\end{array}$ & $\begin{array}{r}11 \\
1 \\
6 \\
3 \\
3 \\
4 \\
1\end{array}$ & $\begin{array}{l}5 \cdot 2 \\
1.4 \\
2 \cdot 2 \\
1.8 \\
0 \cdot 4 \\
0 \cdot 5 \\
0 \cdot 1\end{array}$ & $\begin{array}{l}3 \\
0 \\
1 \\
0 \\
1 \\
2 \\
0\end{array}$ & $\begin{array}{l}4 \\
1 \\
3 \\
3 \\
0 \\
0 \\
1\end{array}$ & $\begin{array}{l}4 \\
0 \\
2 \\
0 \\
2 \\
2 \\
0\end{array}$ \\
\hline \multirow[t]{2}{*}{ All causes } & $\underbrace{12}$ & $5 \cdot 3$ & $\underbrace{3(1.4)}$ & $5(1.8)$ & $4(2 \cdot 1)$ \\
\hline & \multicolumn{2}{|c|}{$p<0.003$} & NS & $\underbrace{9(3.9)}_{p<0.001}$ & \\
\hline
\end{tabular}

The number of deaths observed in each group according to cause and the degree of vagal neuropathy are also shown; expected number of deaths are shown in brackets.

ther statistical analysis. There were no significant differences between the ages, drinking history, occurrance of central and peripheral nervous damage or liver disease and follow up periods between the three groups (table 1). The tests that gave the highest frequency of abnormal results in the subjects with one or more abnormal tests were the 30:15 ratio after standing and the change of heart rate during deep breathing.

\section{Mortality}

Of the 79 subjects who were examined 12 subjects died during the 7 year follow-up period. The causes of death and the numbers of deaths observed according

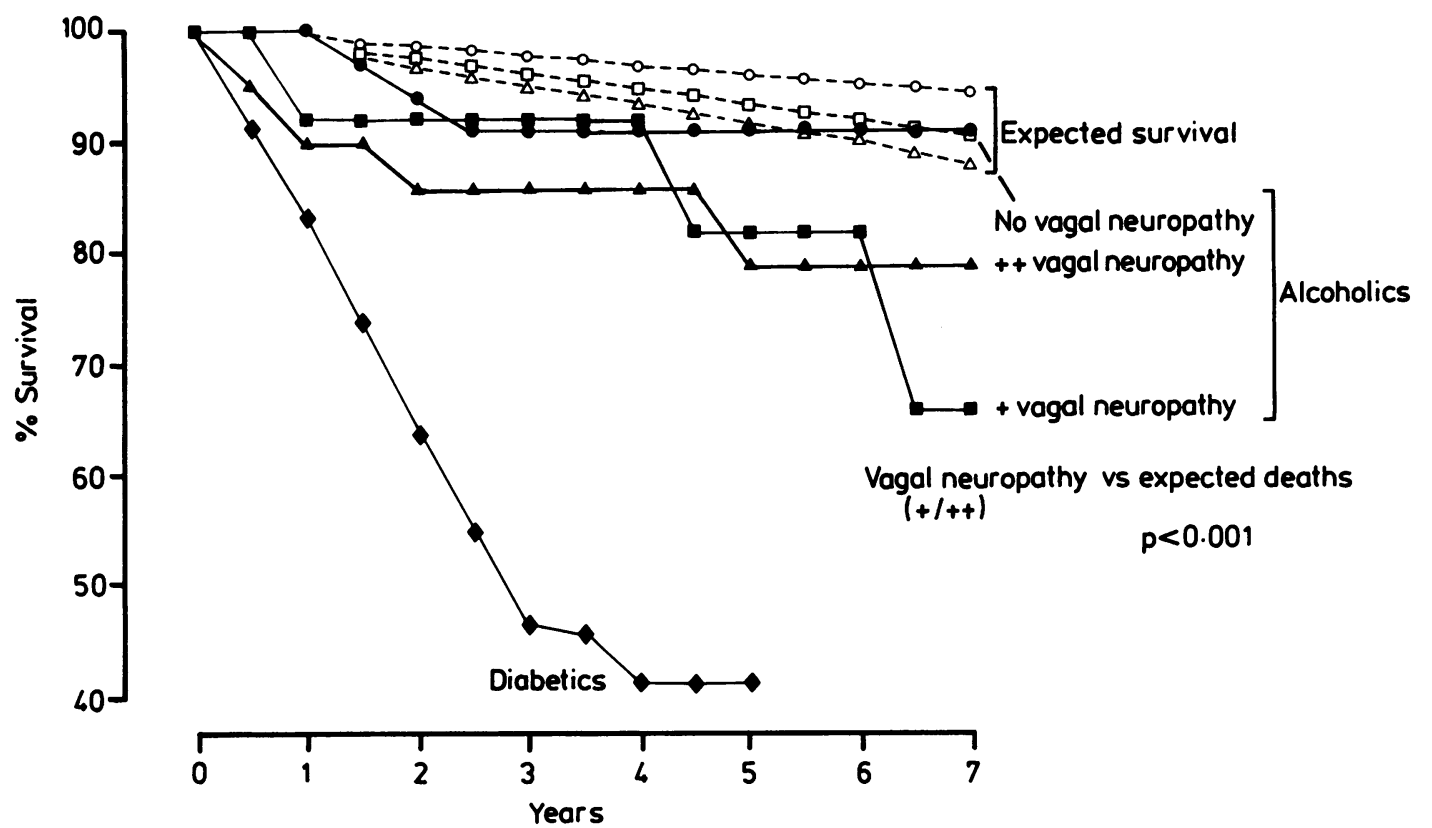

Fig Seven year survival curves for alcoholics upon whom autonomic function tests were carred out. 32 alcoholics had no evidence of parasympathetic neuropathy (O), 25 alcoholics had only one abnormal test ( $\square$ ) and 22 alcoholics had two or more abnormal tests ( $\mathbf{\Delta}$ ). Expected survival curves for the general New Zealand population are shown by broken lines with age matching for each group (open symbols). Survival curve for a diabetic population with autonomic neuropathy ${ }^{7}$ is also shown ( ). The survival rate of alcoholics who had evidence of parasympathetic neuropathy was significantly decreased $(p<0.001)$. 
to degree of vagal neuropathy and expected numbers of deaths calculated from national statistics are shown in table 2 . There was a significantly increased number of deaths $(12, p<0.003)$, in the total group of alcoholic subjects when compared with the expected number of deaths $(5 \cdot 3)$ from an age and sex matched population. The nine deaths observed in the subjects with one or more abnormal vagal function tests were significantly greater when compared with the expected number $(3.9, p<0.001)$ of deaths for their combined groups. Subjects who had four normal vagal function tests did not have a significantly $(p=0 \cdot 16)$ different number of deaths (3) when compared with an age matched population $(1 \cdot 4)$. The calculated percentage survivals over the 7 year follow-up period are shown in the fig. The subjects with no evidence of vagal neuropathy had $91 \%$ survival at 7 years. The subjects who had one abnormal vagal function test result had $66 \%$ survival at 7 years and the subjects who had two or more abnormal vagal function results had $79 \%$ survival at 7 years. There was a significant increase in deaths due to respiratory $(\mathrm{p}<0.001)$ and cardiovascular $(p=0.009)$ diseases in the total group of all alcoholic subjects. The total number of deaths due to cardiovascular disease in the subjects without evidence of vagal neuropathy was not significantly raised ( 1 death observed, 0.44 expected; $p=0.39$ ) however the numbers of these deaths was significantly raised in the subjects who had one or more abnormal vagal function test results (5 deaths observed, 1.76 deaths expected; $p=0.013$ ).

The number of observed deaths due to cerebrovascular disease (3) was significantly higher $(p<0.001)$ in the total group of alcoholics than the number expected from a general age matched population.

\section{Discussion}

The tests which showed the greatest number of abnormal results were heart rate changes with deep breathing and on standing (30:15 ratio) whereas the Valsalva manoeuvre gave the lowest (table 1). In all tests, however, the apparent sensitivity depends upon the level taken as the lower limit of normal values. In this paper we have taken previously reported values for each test. Our observations suggest however, that the lower limit of normal values for the HR ratio derived from Valsalva's manoeuvre should be closer to that originally recommended $(>1.5)$ by Levin, ${ }^{10}$ or perhaps $>1.4$ rather than the more recently recommended figure of $>1 \cdot 2$, which we have used.

The excess number of observed deaths compared to the expected number of deaths we have observed was amongst the alcoholics who had evidence of vagal neuropathy using the values for normality recommended by previous workers. In a similar study of diabetics, increased mortality was also found in those who had evidence of autonomic neuropathy. ${ }^{718}$ The survival of diabetics with autonomic neuropathy was less than that of our alcoholics with vagal neuropathy observed in this study (fig). The higher mortality observed in diabetics with autonomic neuropathy may be due to several factors. First, $50 \%$ of the observed deaths in Ewings study ${ }^{7}$ were attributed to renal failure; a frequent problem in diabetics although rare in alcoholics. Second, the progression of autonomic neuropathy in diabetics is different from that in alcoholics. In diabetics once cardiovascular tests are found to be abnormal, there is no reversal ${ }^{7}$ whereas chronic alcoholics with vagal neuropathy may have improvement of vagal function tests following continued abstinence. ${ }^{8}$ The lower mortality rate amongst alcoholics with vagal neuropathy may therefore reflect long periods of abstinence or complete abstinence in several of the subjects. Third, the increased rate of mortality in diabetics may reflect the fact that autonomic neuropathy in diabetics affects sympathetic and parasympathetic nerve pathways whereas alcoholics generally have evidence of parasympathetic neuropathy only.

Orthostatic hypotension was observed in only two subjects. It was unlikely to be due to acute blood volume changes following withdrawal and it was observed after at least 6 weeks of abstinence and was probably due to sympathetic failure as this occurs in some similar patients ${ }^{6}$ but is nevertheless rare in alcoholics. ${ }^{19}$ Our observations indicate that alcoholic autonomic neuropathy primarily affects the parasympathetic pathways rather than the sympathetic pathways.

Autonomic neuropathy in chronic alcoholism has been recognised both clinically ${ }^{20}$ and pathologically ${ }^{2}$ although the consequences of alcoholic neuropathy as a cause of significant changes in autonomic nervous reflexes has previously been considered insignificant. ${ }^{5}$ However, more recently alcoholic autonomic neuropathy, particularly damage to the parasympathetic pathways, has been shown to have pathophysiological effects on cardiovascular reflexes, ${ }^{1}$ pupillary function, ${ }^{21}$ sexual impotence ${ }^{22}$ and sleep apnoea. ${ }^{23}$

The majority of the deaths observed in our series were sudden or unexplained. Several deaths were attributed to stroke and it has been recognised that heavy alcohol consumption is an important risk factor in the occurrence of stroke. ${ }^{24}$ Another factor in the occurrence of stroke may be a reduction of effective intravascular volume in alcoholics who have vagal neuropathy and liver damage. ${ }^{25}$ There is an association between cerebral infarction and snoring due to partial airway obstruction ${ }^{26}$ and there is a high incidence of sleep apnoea in withdrawn alcoholics. ${ }^{23}$ Increased incidence of central and obstructive apnoea and hypopnea is associated with central nervous system damage and vagal neuropathy in alcoholics. ${ }^{23}$ 
Acute ingestion of alcohol increases the frequency of abnormal respiratory events during sleep in normal subjects $^{27}$ and patients with sleep-induced upper airway occlusion ${ }^{28}$ and we have recently shown that this applies to alcoholics as well. Acute ingestion of alcohol may cause atrial fibrillation and stroke. ${ }^{29-31}$ Cardiomyopathy resulting from chronic alcohol abuse may also be another cause of atrial fibrillation. ${ }^{32}$ Although the direct causative relationship of vagal neuropathy in the mortality of individual patients is generally unclear our results imply that its presence is indicative of a reduced chance of long term survival.

This study was supported by the Wellington Medical Research Foundation. We thank Dr E A Whiteside for his help with this study.

\section{References}

1 Duncan G, Johnson RH, Lambie DG, Whiteside EA. Evidence of vagal neuropathy in chronic alcoholics. Lancet 1980;ii: 153-7.

2 Novak DJ, Victor $M$. The vagus and sympathetic nerves in alcoholic polyneuropathy. Arch Neurol 1974;30:273-84.

3 Johnston LC, Patel S, Vankineni P, Kramer N. Deficient slowing of the heart among very heavy social drinkers. J Stud Alcohol 1983;44:505-14.

4 Melgaard B, Somnier F. Cardiac neuropathy in chronic alcoholics. Clin Neurol Neurosurg 1981;83:219-24

5 Low PA, Walsh JC, Huang CY, McLeod JG. The sympathetic nervous system in alcoholic neuropathy: a clinical and pathological study. Brain 1975;98:357-64.

6 Eisenhofer G, Whiteside EA, Johnson RH. Plasma catecholamine responses to change of posture in alcoholics during withdrawal and after continued abstinence from alcohol. Clin Sci 1985;68:71-8.

7 Ewing DJ, Campbell IW, Clarke BF. The natural history of diabetic autonomic neuropathy. $Q J$ Med 1980;49:95-108

8 Tan ETH, Johnson RH, Lambie DG, Whiteside EA. Alcoholic vagal neuropathy: recovery following prolonged abstinence. $J$ Neurol Neurosurg Psychiatry 1984;47:1335-7.

9 Ewing DJ, Campbell IW, Murray A, Neilson JMW, Clarke BF Immediate heart rate response to standing: a simple test for autonomic neuropathy in diabetes. $\mathrm{Br}$ Med $J$ 1978;i:145-7.

10 Levin AB. A simple test of cardiac function based upon the heart rate changes induced by the Valsalva manoeuvre. Am J Cardiol 1966;18:90-9.
11 Ewing DJ, Campbell IW, Burt AA, Clarke BF. Vascular reflexes in diabetic autonomic neuropathy. Lancet 1973;ii:1354-6.

12 Wheeler T, Watkins PJ. Cardiac denervation in diabetes. $\mathrm{Br} \mathrm{Med}$ J 1973;iv:584-6.

13 Ewing DJ. Practical bedside investigation of diabetic autonomic failure. In: Bannister RD, ed. Autonomic Failure. Oxford: University Press, 1983:371-405.

14 Mackay JD, Page MM, Cambridge J, Watkins PJ. Diabetic autonomic neuropathy. The diagnostic value of heart rate monitoring. Diabetologia 1980;18:471-8.

15 Chamberlain DA, Turner P, Sneddon JM. Effects of atropine on heart-rate in healthy man. Lancet 1967;ii:12-5.

16 Bradford-Hill A. A Short Textbook of Medical Statistics. London: Hodder and Stoughton, 1977.

17 Peto R, Pike MC, Armitage P. Design and analysis of randomized clinical trials requiring prolonged observation of each patient. II-Analysis and examples. $\mathrm{Br} J$ Cancer 1977;35:1-39.

18 Ewing DJ, Campbell IW, Clarke BF. Mortality in diabetic autonomic neuropathy. Lancet 1976;i:601-3.

19 De Marchi S, Cecchin E. Are orthostatic hypotension and impaired blood pressure control common features of the alcohol withdrawal syndrome? Clin Sci 1986;70:213-4.

20 Barraclough MA, Sharpey-Schafer EP. Hypotension from absent circulatory reflexes. Lancet 1963;i:1121-6.

21 Tan ETH, Lambie DG, Johnson RH, Whiteside EA. Parasympathetic denervation of the iris in alcoholics with vagal neuropathy. J Neurol Neurosurg Psychiatry 1984;47:61-4

22 Tan ETH, Johnson RH, Lambie DG, Vijayasenan ME, Whiteside EA. Erectile impotence in chronic alcoholics. Alcoholism 1984;8:297-301.

23 Tan ETH, Lambie DG, Johnson RH, Robinson BJ, Whiteside EA. Sleep apnoea in alcoholic patients after withdrawal. Clin Sci 1985;69:655-61.

24 Gill JS, Zezulka AV, Shipley MJ, Gill SK, Beevers DG. Stroke and alcohol consumption. $N$ Engl J Med 1986;315:1041-6.

25 Decaux G, Cauchie P, Soupart A, Kruger M, Delwiche F. Role of vagal neuropathy in the hyponatraemia of alcoholic cirrhosis. Br Med J 1986;293:1534-6.

26 Partinen $M$, Palomaki $H$. Snoring and cerebral infarction. Lancet 1985;ii:1325-6.

27 Taasan VC, Block AJ, Boysen PG, Wynne JW. Alcohol increases sleep apnoea and oxygen desaturation in asymptomatic men. Am J Med 1981;71:240-5.

28 Issa FG, Sullivan CE. Alcohol, snoring and sleep apnoea. $J$ Neurol Neurosurg Psychiatry 1982;45:353-9.

29 Wolf PA, Dawber TR, Thomas HE, Kannel WB. Epidemiological assessment of chronic atrial fiberillation and risk of stroke: The Framingham Study. Neurology 1978;28:973-7.

30 Thornton JR. Atrial fibrillation in healthy non-alcoholic people after an alcoholic binge. Lancet 1984;ii:1013-5.

31 Rich EG, Siebold C, Campton B. Alcohol-related acute atrial fibrillation. Arch Int Med 1985;145:830-3.

32 Brigden W, Robinson J. Alcoholic heart disease. $\mathrm{Br}$ Med J 1964;ii:1283-9. 